\title{
Method for Simulating the Impact of Runoff-inundation / Short Localized Downpours in the Vicinity of Railway Tracks
}

Ryo MANOME

Satoshi WATANABE

Geo-hazard \& Risk Mitigation Laboratory, Disaster Prevention Technology Division

The recent rise in short, localized high-intensity torrential rainfall events leading to flooding from rivers, has generated a growing number of disasters affecting urban areas. Japan's railways restrict train operations according to precipitation and river water levels, however, these traffic control methods have not yet been adapted to cope with such short, intense downpours. A real-time rainfall runoff-flooding simulation method, which takes into account predicted rainfall therefore needs to be developed. This paper reports on evaluation results obtained to validate a simulation method.

Keywords: runoff analysis, flooding analysis, river, Digital Elevation Model (DEM)

\section{Introduction}

The climate is changing on a global scale, leading to short, frequent and heavy localized downpours. In urban areas, damage, such as inundation, is caused by rivers bursting their banks and road flooding due to excess inland water. In order to maintain safety, railway operations are generally controlled in the light of threshold values determined mainly by observed rainfall values and river levels. However, short localized heavy downpours occur within a range of 10 kilometers, moving a few kilometers in a short time. Current observation systems are unable to detect the flooding that occurs in such a short time from brief, localized heavy rain, and as a consequence, traffic control management methods that look at the influence of weather on trains and passengers, have not yet been established. Nevertheless, developments in meteorological observation and prediction technologies, means that it has become possible to predict with high accuracy, changes in rain-affected areas and rainfall with a lead time of one to two hours [1]. This study therefore aims to develop an inundation / flooding hazard mapping system that can be used in real time with input from forecasts of localized heavy rain, with a lead time of several tens of minutes to several hours, for use in conjunction with railway traffic control systems [2]. This paper describes the outline of the runoff / flooding analysis method used for the analysis of disaster hazards, and results from examining Digital Elevation Model (DEM) resolutions, in relation to analysis accuracy and analysis time.

\section{Outline of runoff / flooding analysis method and preconditions}

Figure 1 shows the calculation flow for the runoff / flooding analysis. The analysis model uses DEM to reproduce a sectional shape of the river. When an arbitrary rainfall is input as a condition to the DEM, rainwater flows into the river model along the inclination of the terrain ( (1) basin analysis in Fig. 1). In the river model, the river flow rate and the water level are calculated sequentially from the volume of inflowing rainwater. When the river flow rate increases and the water level of the river exceeds the bank height, the river overflows ( (2) analysis of the river in Fig. 1). The overflowing water diffuses or floods according to the topography in the DEM ( (3) flooding analysis in Fig. 1).

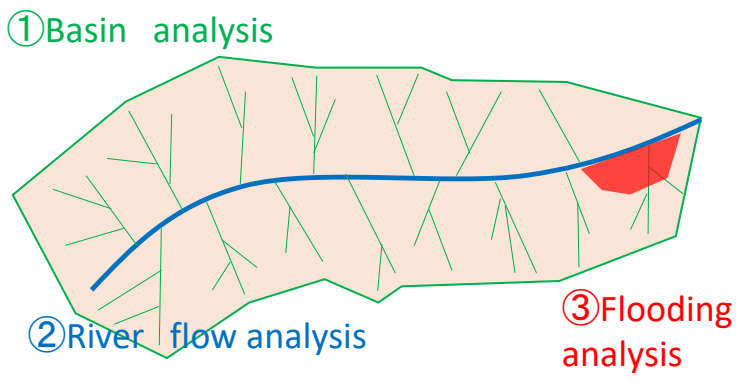

Fig. 1 Diagram of runoff / flooding analysis

\section{Expression of the runoff / flooding analysis model}

The outflow phenomenon in the watershed analysis is based on the distributed runoff model [3]. The relationship between the unit width flow rate $q$ flowing down the slope and the water depth $h$ is expressed by the following equation.

$$
\begin{aligned}
& q(h)=\sqrt{\frac{i}{n_{\text {slope }}}} \cdot h^{m} \\
& \frac{\partial h}{\partial t}+\frac{\partial q}{\partial x}=r(t)
\end{aligned}
$$

$q(h)$ : unit width flow rate;

i : ground surface gradient;

$\mathrm{n}_{\text {slope }}$ : ground surface equivalent roughness;

$\mathrm{m}$ : constant;

$\mathrm{x}$ : slope downflow direction; and

$r(t)$ : rainfall intensity.

The rainwater is tracked by a differential solution obtained by combining the continuous equations represented by (1) and (2).

For river analysis, rainwater flowing into a river calculated by the above method flows downward as a onedimensional unsteady flow represented by the following 
equations (3) to (5).

$$
\begin{gathered}
\frac{\partial A}{\partial t}+\frac{\partial Q}{\partial x}=0 \\
\frac{\partial Q}{\partial t}+\frac{\partial\left(Q^{2} / A\right)}{\partial x}+g A \frac{\partial H}{\partial x}+\frac{T_{r}}{\rho}=0 \\
\frac{T_{r}}{\rho}=\frac{g Q|U|}{R^{4 / 3}}\left(\frac{\sum_{i} P_{w i} n_{i}^{3 / 2}}{\sum_{i} P_{w i}}\right)^{4 / 3}
\end{gathered}
$$

A : water flow cross section;

$\mathrm{Q}$ : flow rate;

$\mathrm{U}$ : flow velocity;

$\mathrm{H}$ : water level;

g: gravitational acceleration;

Tr : Unit length force acting on the riverbed;

$\mathrm{P}$ : Density of water;

$\mathrm{n}_{\mathrm{i}}$ : Manning roughness coefficient in the section $\mathrm{i}$;

$\mathrm{P}_{\mathrm{wi}}$ : Wetted perimeter;

$\mathrm{R}_{\mathrm{wi}}$ : Hydraulic radius;

$\mathrm{x}$ : crossing direction of the river;

$\mathrm{z}$ : vertical direction; and

$\mathrm{y}:$ flow direction.

Flooding occurs when the rate of the flow that flows down in the river cross section exceeds the allowable amount. In the flooding analysis, the flood water flows down the ground surface as a two-dimensional unsteady flow obtained by the equations (6) - (8) [4]. This calculation method is based on the equation of motion taking into consideration the field acceleration, the inertia term, the water surface gradient term, and the resistance term.

$$
\begin{gathered}
\frac{\partial h}{\partial t}+\frac{\partial M}{\partial x}+\frac{\partial N}{\partial y}=Q_{i n} \\
\frac{\partial M}{\partial t}+\frac{\partial(u M)}{\partial x}+\frac{\partial(v M)}{\partial y}=-g h \frac{\partial H}{\partial x}-\frac{g n^{2} u \sqrt{u^{2}+v^{2}}}{h^{1 / 3}} \\
\frac{\partial M}{\partial t}+\frac{\partial(u N)}{\partial x}+\frac{\partial(v N)}{\partial y}=-g h \frac{\partial H}{\partial y}-\frac{g n^{2} v \sqrt{u^{2}+v^{2}}}{h^{1 / 3}}
\end{gathered}
$$

$Q_{\text {in }}$ : flow rate flowing into or out of the system; $\mathrm{h}:$ depth of water; $\mathrm{t}$ : time;

$\mathrm{M}$ and $\mathrm{N}$ : Flow flux in $\mathrm{x}$ and $\mathrm{y}$ direction $(\mathrm{M}=\mathrm{uh}, \mathrm{N}=\mathrm{vh})$; $\mathrm{u}$ and $\mathrm{v}$ : flow rate fluxes in the $\mathrm{x}$ and $\mathrm{y}$ directions; $\mathrm{g}:$ gravitational acceleration;

$\rho$ : density of water; and

$\mathrm{n}$ : floodplain roughness coefficient.

The second and third terms on the left side of the equations (7) and (8) are advection terms.

\section{Analysis accuracy of the runoff / flooding analysis model}

\subsection{Target area and rainfall}

A location along the railway line with a history of inundation from nearby rivers was selected as the target analysis area. The outflow / flood analysis model described above was then applied to the area.

Figure 2 shows the outline of the target analysis area. The target river flowed east to west with a channel extension of $25.2 \mathrm{~km}$ and a catchment area of $61.6 \mathrm{~km}^{2}$, with the railway running almost parallel to the river. Only the basin on the upstream side of the river crossed by the railway is shown in the figure. The downstream side was not modeled, and the rainwater having reached the end of the stream was set as the boundary condition to dissipate. As shown in the figure, the railway crosses the river over a bridge in one location to the east. DEM is used to express the topography for the area inside the red box, to an accuracy of $1 \mathrm{~m}$, whereas elsewhere the accuracy was to $5 \mathrm{~m}$ based on data from the Geographical Survey Institute.

The input condition was the Tokai downpour (total rainfall, $589 \mathrm{~mm}$; maximum rainfall per hour, $114 \mathrm{~mm}$ ),

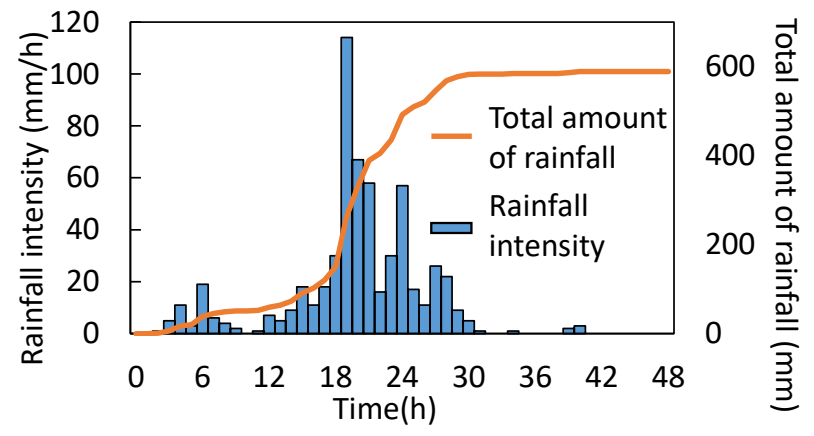

Fig. 3 Hyetograph of Tokai heavy rain

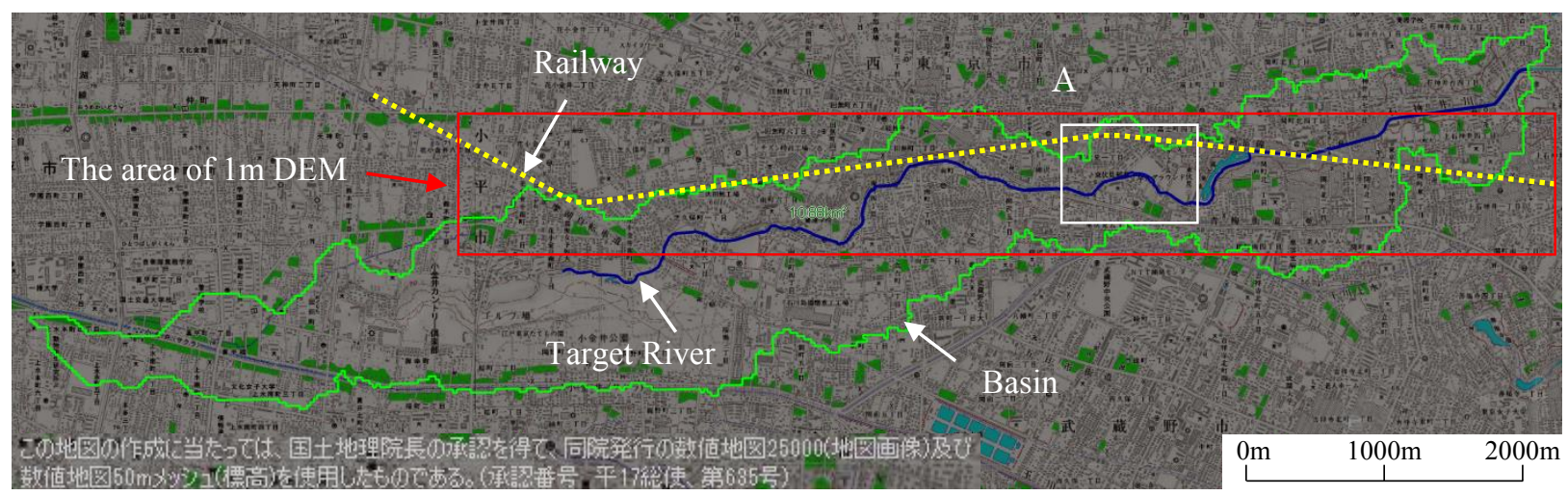

Fig. 2 Outline of the target area for analysis 
which occurred in September 2000 and caused extensive damage in the Tokai region (Fig. 3). The runoff / flooding analysis was performed by changing the size of the DEM grids to $5 \mathrm{~m}, 25 \mathrm{~m}, 50 \mathrm{~m}$, and $100 \mathrm{~m}$.

\subsection{Comparison of runoff and flooding analysis mod- el results with calculated examples using the Digital Surface Model (DSM)}

As shown in Fig. 2, there are places where high resolution DEM data was acquired using a laser profiler in the basin. Therefore, assuming that the calculation results using the $1 \mathrm{~m}$ DEM were the most realistic, it could confirm the error margin that would appear in the analytical results were the accuracy lowered by increasing the DEM grid size. The DEM grid size for the analysis was $1 \mathrm{~m}$, and a Digital Surface Model (DSM) expressing the actual height of the building etc. was used (Fig. 4). The input conditions were similar to those used in the case described in Section 4.1 .

Figure 5 shows the enlarged aerial photographs of part A in Fig. 2 in relation to the analytical results using the 5 $\mathrm{m}, 25 \mathrm{~m}, 50 \mathrm{~m}$ and $100 \mathrm{~m} \mathrm{DEM}$ on the basis of a $1 \mathrm{~m} \mathrm{DEM}$. For comparison with the topography, all the terrains displayed in the background were $1 \mathrm{~m}$ DEM.

The reference analysis results using $1 \mathrm{~m}$ DSM data almost complied with the actual height and shape of the

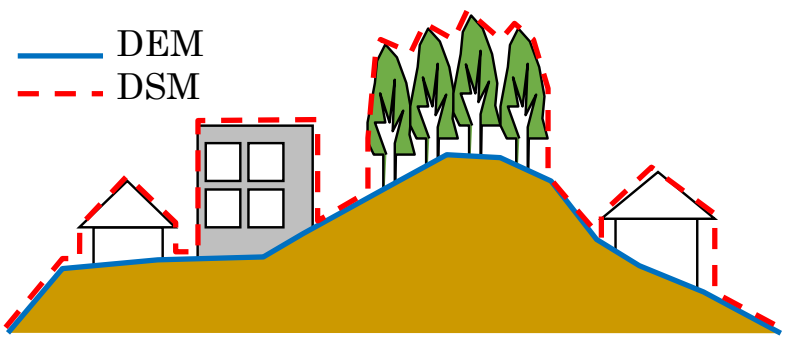

Fig. 4 Difference between DEM and DSM land, as indicated by the red dashed line in the figure: roads between buildings, wide road sections, and the ground were flooded. Maximum depth flooding in the range of 1.0 to $2.0 \mathrm{~m}$ was widely distributed. When comparing the shape of the aerial photo and the DEM displayed in the background with the inundation range, the flooded area appears to take into account buildings. In the analysis results using $5 \mathrm{~m}$ DEM the buildings are not taken into consideration, therefore the flooding spreads to these site with relatively shallow maximum flooded depth of 0.5 to $1.0 \mathrm{~m}$. However, the overall flooding area almost agrees with the results of the reference analysis using 1m DSM, and the accuracy of the $5 \mathrm{~m}$ DEM around the river and its shape are similar to the results from the 1m DSM. Analysis results using a $25 \mathrm{~m}$ DEM show a lower level of accuracy than when a $5 \mathrm{~m}$ DEM is used, but they still reveal a similar trend.

Results from the analysis using a $50 \mathrm{~m}, 100 \mathrm{~m}$ DEM contradict the results of the background DEM, when comparing the topography of B part in Fig. 5, and flooding is shown to reach elevated locations. Therefore, as the DEM grid size is increased, the flooding range is more approximate, and the maximum flood depth also shows noticeable variations ranging from $0.2 \mathrm{~m}$ or less, to $2.0 \mathrm{~m}$ or more.

For reference, the yellow dashed line (only showing DEM grid size $1 \mathrm{~m}$ and $100 \mathrm{~m}$ ) in Fig. 5, shows the outer perimeter of the flooded area when DEM was $5 \mathrm{~m}, 25 \mathrm{~m}, 50 \mathrm{~m}$, $100 \mathrm{~m}$ compared with a DEM of $1 \mathrm{~m}$, giving areas that were $103 \%, 103 \%, 118 \%$ and $155 \%$ of the DEM at $1 \mathrm{~m}$, respectively.

From the above, an analysis using a $1 \mathrm{~m} \mathrm{DSM}$ is assumed to give the most realistic values, and the inundation ranges found through analyses using $25 \mathrm{~m}$ or more DEM are almost the same. However, since DEM analyses do not take buildings into account, there is a possibility of underestimating the maximum flooding depth.
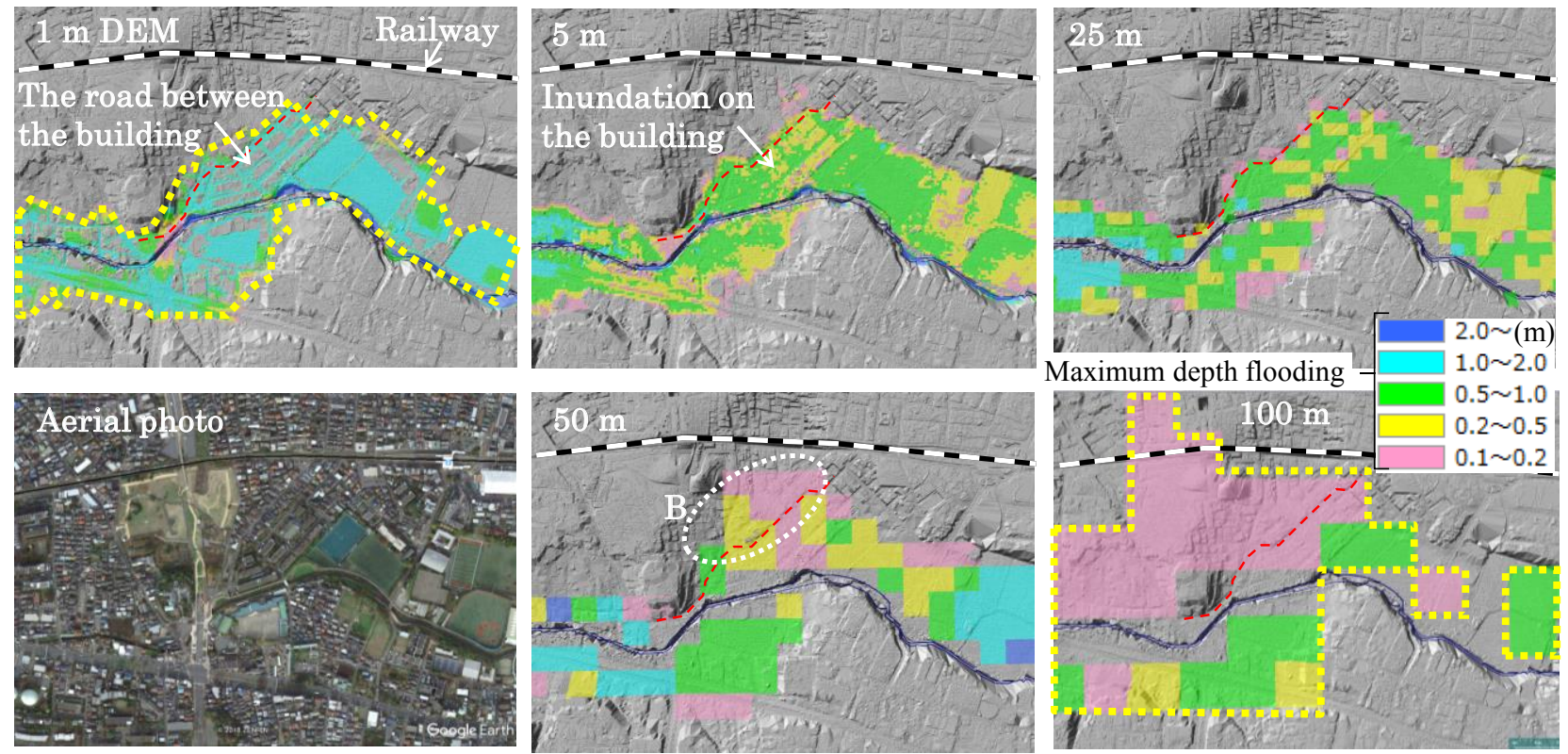

Fig. 5 Enlarged drawings of "A" in Fig. 2 (Aerial photos extracted from Google maps) 


\section{Calculation load for runoff / flooding analysis}

In developing a series of systems [2] which will determine the stopping position of trains through analysis, taking into consideration the flooding range found using the results of the runoff / flooding analysis with forecast precipitation as input (5), the analysis must be as accurate and as fast as possible. Therefore, an investigation was carried out to find the resources that would be required for the calculation with the DEM grid size a parameter and measured actual rainfall as the basic data.

Table 1 shows a list of the examined downpours, while Fig. 6 is a hyetograph for each rainfall. The Tokai downpour has already been introduced above. In addition, recent localized violent downpours were selected. Table 2 summarizes the relationship between the DEM grid size and the calculation time. The platform used for the calculation was a PC with Intel (R) Core ${ }^{\mathrm{TM}}$ i7-4770 CPU @ 3.4 $\mathrm{GHz} 3.4 \mathrm{GHz}, 4$ cores / 8 Threads, 32.GB RAM.

Table 2 shows that the computation time increased as the DEM grid size decreased and the duration of the downpour increased. Target analysis times of 30 minutes or less were supposed to be shaded as a guide, however, with a 1 $\mathrm{m}$ DEM, it can be seen that each case exceeded 30 minutes by a long margin.

In this study it is assumed that forecast precipitation values with lead times of several tens of minutes to several hours were used as input; but it is necessary to minimize the downtime considering the time required for this data to be communicated and for the train stopping position to be determined through analysis, etc. For example, even if predicted values are obtained with a lead time of 1 hour, if 30 minutes are required to produce the final calculation results, the practical lead time will in fact only be 30 minutes. As such, the $25 \mathrm{~m}$ DEM was selected as the standard, since it was considered to have an acceptable level of accuracy for the present time. In future however, as the time required for analysis is shortened with better performing
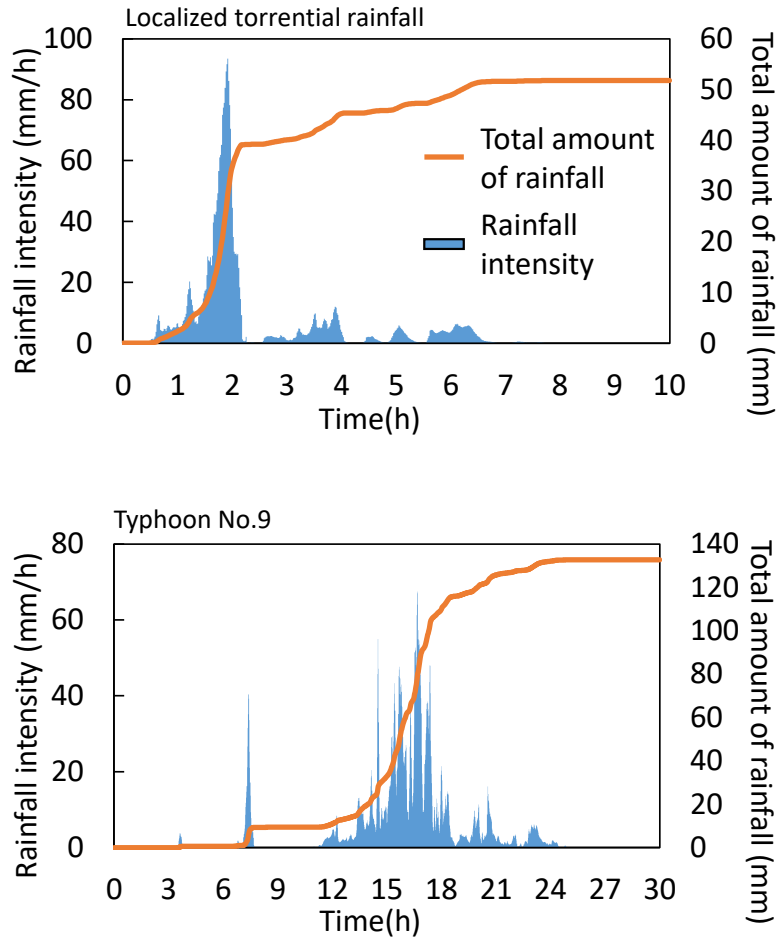

Fig. 6 Hyetograph of Localized torrential rainfall and Typhoon No. 9

Table 1 List of downpours used for analysis

\begin{tabular}{|c|rrr|c|}
\hline Rainfall & \multicolumn{2}{|c|}{ duration of rain } & $\begin{array}{c}\text { 3 hours added to } \\
\text { each period of rain }\end{array}$ \\
\hline Localized torrential rainfall & 19th August $2017 \quad 15: 00 \sim 20$ th August $2017 \quad 1: 00$ & 13 \\
\hline Typhoon No. 9 & 21st August 2016 & $18: 00 \sim 23$ rd August 2016 & $0: 00$ & 33 \\
\hline Tokai heavy rain & 4th September 2005 $\quad 19: 00 \sim 6$ th September 2005 19:00 & 51 \\
\hline
\end{tabular}

Table 2 Computation time according to DEM grid size (No impact on rail services from rainfall)

\begin{tabular}{|c|c|c|c|c|}
\hline Rainfall & $\begin{array}{c}\text { Period of } \\
\text { analysis (hour) }\end{array}$ & $\begin{array}{c}\text { Volume of rain } \\
(\mathrm{mm})\end{array}$ & DEM grid size (m) & Analysis time (min) \\
\hline \multirow{3}{*}{ Localized torrential rainfall } & \multirow{3}{*}{13} & \multirow{3}{*}{52} & 1 & 305.9 \\
\hline & & & 5 & 1.9 \\
\hline & & & 25 & 0.1 \\
\hline \multirow{3}{*}{ Typhoon No. 9} & \multirow{3}{*}{48} & \multirow{3}{*}{133} & 1 & 553.9 \\
\hline & & & 5 & 9.8 \\
\hline & & & 25 & 0.3 \\
\hline \multirow{3}{*}{ Tokai heavy rain } & \multirow{3}{*}{51} & \multirow{3}{*}{589} & 1 & 2485.5 \\
\hline & & & 5 & 102.4 \\
\hline & & & 25 & 1.5 \\
\hline
\end{tabular}


PCs, it may become necessary to shorten the analysis time by decreasing the DEM grid size.

\section{Conclusions}

This paper compares results obtained through analysis with values obtained with gradually increased DEM grid sizes from $1 \mathrm{~m}$ to $100 \mathrm{~m}$, and with the results of a $1 \mathrm{~m}$ DSM, considered to give results closest to reality, in order to validate a runoff / flooding analysis model. Findings showed that when the DEM grid size was less than $25 \mathrm{~m}$, flooding areas generally agreed, and the maximum flooding depth was evaluated to be somewhat lower because the model did not take into consideration structures and trees. When the DEM grid size was increased to $50 \mathrm{~m}, 100 \mathrm{~m}$, the difference in maximum flooding depth became noticeable, and the flooding range contradicted the elevation difference in the $1 \mathrm{~m}$ DEM topography. In order to systematize the method, the relationship between the rainfall scale and the calculation load was examined. It was found that in future, it will be necessary to understand the load put on calculation resources when installing detailed drainage facilities and to improve the accuracy of outflow / flood analysis by data assimilation with actual water level measurement data. It will also be necessary to examine what the optimum evaluation will be of the influence of flooding on elevated sections and high embankment sections, where flooding would not influence railway operation s, etc. even when inundation occurs.

\section{Acknowledgement}

This research was partly funded by the Cabinet Office SIP (Cross-ministerial Strategic Innovation Promotion Program), of the Government of Japan.

\section{References}

[1] Japan Meteorological Agency, High resolution precipitation now cast (Last viewed date : $8^{\text {th }}$, March, 2018) (http://www.jma.go.jp/jma/kishou/know/kurashi/ highres_nowcast.html).

[2] Naoya, O., Takuya, W., Noriko, F., "Algorithm of Train Operation Control and Passenger Evacuation Based on Forecast of Tornado and Flood," RTRI Report, Vol.31, No.10, pp.5-10, 2017.

[3] Yasuto, T., Gen, N., Kaoru, T., "Development of Stage-Discharge Relationship Equation Incorporation Saturated-Unsaturated Flow Mechanism," Proceedings of hydraulic engineering, vol. 48, pp. 7-12, 2004.

[4] The Collection of Hydraulic Formulae. Japan Society of Civil Engineers, pp. 97 formula (2-2.21), 1999 (in Japanese).

\section{Authors}

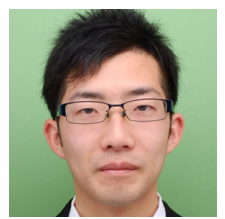

Ryo MANOME

Researcher, Geo-hazard \& Risk Mitigation

Laboratory, Disaster Prevention Technology

Division

Research Areas: Rainfall Disaster

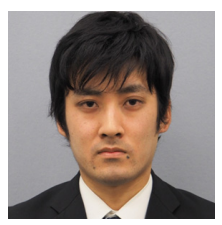

Tomoki YUASA

Researcher, Geo-hazard \& Risk Mitigation Laboratory, Disaster Prevention Technology Division

Research Areas: Rainfall Disaster

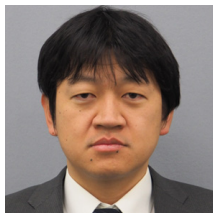

Satoshi WATANABE

Senior Researcher, Geo-hazard \& Risk

Mitigation Laboratory, Disaster Prevention

Technology Division

Research Areas: Rainfall Disaster 